\title{
Prevalence of radiographic asbestosis in crocidolite miners and millers at Wittenoom, Western Australia
}

\author{
W O C M COOKSON, N H DE KLERK, A W MUSK, B K ARMSTRONG, \\ J J GLANCY, AND M S T HOBBS
}

\begin{abstract}
From the Departments of Respiratory Medicine and Diagnostic Radiology, Sir Charles Gairdner Hospital, Nedlands, the National Health and Medical Research Council Research Unit in Epidemiology and Preventive Medicine, and Unit of Clinical Epidemiology, University of Western Australia, Perth, Western Australia
\end{abstract}

\begin{abstract}
An estimate has been made of the prevalence of unrecognised pneumoconiosis in former crocidolite workers from Wittenoom, Western Australia. All plain chest radiographs relating to a one in six random sample (1025 men) of all former Wittenoom workers who had never entered a compensation claim to the Pneumoconiosis Medical Board of Western Australia were sought from Perth teaching hospitals and from the Perth Chest Clinic where compulsory examination of all workers in the mining industry takes place. Radiographs were recovered for $83 \%$ of the men and read independently by two observers. By means of logistic regression analysis a current prevalence of parenchymal abnormality (defined as a radiographic profusion of small opacities of category $1 / 0$ or greater on the ILO classification) of nearly $20 \%$ was calculated after adjustment for age, time since first exposure, and cumulative exposure level. One hundred men randomly selected from those known to be alive in the sample were invited to attend for a new radiographic examination. Seventy four men attended and the predicted prevalence was confirmed. It is estimated from these data that there were between 450 and 900 former Wittenoom workers in Australia at the end of 1980 who had radiographic abnormality consistent with pneumoconiosis but had not claimed compensation or had asbestosis diagnosed. The data are consistent with there being no threshold dose of crocidolite exposure for the development of radiographic abnormality in this group.
\end{abstract}

A single company operated the Wittenoom crocidolite mine and mill in the Pilbara region of Western Australia between 1943 and 1966. The employment records of the company identifying nearly 7000 workers have been retained and form the basis of a continuing study of the workforce. ${ }^{1}$ The mine and mill at Wittenoom operated under conditions of poor industral hygiene that exposed workers to high concentrations of asbestos fibres in inhaled air. ${ }^{2-4}$ By 1978, 220 cases of asbestosis were known to have occurred and $65 \%$ of men who worked in areas classified as "high" exposure for more than five years had received compensation for pneumoconiosis. ${ }^{1} \mathbf{A}$ description of claim established pneumoconiosis has been given elsewhere. $^{5}$

The objective of this study was the estimation of the current prevalence of radiographic pneumoconiosis among former workers at Wittenoom who have not made a claim for compensation. The study is based on the examination of plain chest

Accepted 4 November 1985 radiographs from three sources for a one in six random sample of men from the workforce. Compulsory radiographic examination of workers in the mining industry for pneumoconiosis, an active tuberculosis control programme, doctors' referrals or voluntary presentation for free chest radiographs, and a policy of indefinite preservation of $x$ ray films has led to an invaluable collection of films on many former Wittenoom workers at the Perth Chest Clinic, the first source. Some workers presenting for a variety of reasons after leaving the industry had had chest $x$ ray films retained at Perth teaching hospitals, the second source. Radiographs from these sources were accepted regardless of the reasons for their having been taken. A third set of films was obtained by inviting a random subsample of 100 men from the original sample to attend for an up to date plain chest radiograph. The data from the retrospectively collected radiographs have been used with this current sample to provide a more precise estimate of the prevalence of radiographic abnormality than would otherwise have been possible. 


\section{Subjects}

A random sample of 1025 former Wittenoom male workers who had not previously applied for compensation was selected. The total known population of former workers was 6916 , of whom 354 had applied for compensation; a further 411 were women. The remainder were sampled in the ratio 1:6 regardless of whether they had been traced to Western Australia after finishing work or were known to be still alive.

Plain chest radiographs for these men were sought from the Perth Chest Clinic and Perth teaching hospitals. Radiographs relating to 831 men were recovered from the clinic and to 117 men from the hospitals. Eighty nine subjects had radiographs from both sources. When more than one radiograph taken after the beginning of employment was available from either source the most recent radiograph was chosen for review, one radiograph for each of a total of 859 men.

Additionally, a random sample of 100 men from those men in the whole sample who had previously been contacted within the Perth metropolitan area as part of the continuing study of the total workforce ${ }^{1}$ were invited to attend the Perth Chest Clinic for a further plain chest radiograph. After a maximum of two letters and two telephone calls, 74 of these men attended for examination.

\section{Methods}

\section{CLASSIFICATION OF RADIOGRAPHS}

All radiographs were classified independently by two observers (AWM and JJG) according to the 1980 ILO Classification of Radiographs of Pneumoconioses. ${ }^{6}$ The radiographs of the men invited to attend for examination were randomly mixed with normal and abnormal films from other sources. All radiographs were read without knowledge of exposure details. Agreement between the two readers was tested by Kendall's tau statistic. ${ }^{78}$

\section{ESTIMATION OF EXPOSURE HISTORIES}

The duration and place of work at Wittenoom for each individual has been documented as part of the long term follow up of the Wittenoom cohort. ${ }^{1}$ The concentrations of airborne respirable fibres greater than $5 \mu$ in length in various workplaces at Wittenoom were estimated from the results of a survey undertaken on behalf of the Mines Department of Western Australia in 1966. ${ }^{9}$ Samples for counting the total number of fibres were taken with a Casella long running thermal precipitator. The duration of most samples was between four and five hours. A Casella gravimetric dust sampler and a Hexhlet were used for the collection of dust to estimate mass. Earlier mea- surements of dust concentration using a koniometer had been made at Wittenoom periodically by the Mines Department of Western Australia since 1948. The results from these surveys did not include absolute fibre counts and has an upper limit of 1000 particles per cc. They indicate, nevertheless, that the relative concentrations of total dust in the two mills and two mines have remained similar throughout the life of their operations. The 1966 results have therefore been used to estimate earlier fibre counts, although historical information suggests that absolute counts were higher for mill workers before 1957 when a new mill was built. Total exposure for each individual in fibres/cc years (f/cc y) based on the occupational history and the 1966 fibre counts were estimated up to the time of the plain chest radiograph.

\section{DERIVATION OF A PREDICTIVE MODEL FROM} RETROSPECTIVELY COLLECTED RADIOGRAPHS Radiographic abnormality was taken to be profusion of small opacities on the radiograph of ILO category $1 / 0$ or greater. The relation of this outcome with variables that could have had a predictive effect was first examined in two and three way tables. The variables considered were: age at radiograph (ten year age groups from 15-24 to 65 and over); time since first exposure to asbestos at Wittenoom (not exposed, less than one year, one to four years, then five year intervals to $\mathbf{2 0}$ or more years); total cumulative exposure to asbestos up to time of the radiograph (less than three, three to less than four, four or more $\log _{\mathrm{e}} \mathrm{f} / \mathrm{cc} \mathrm{y}$ ); year of starting work (1943-50, 1951-7, 1958-66); duration of exposure to asbestos at time of radiograph $(0,1-91,92-182,183-365,366-1821,1822$ or more days); and principal work site at Wittenoom (mill, elsewhere). An additional binary variable was included to indicate the source from which the radiograph was obtained (Perth Chest Clinic, teaching hospitals).

A logistic model was the most straightforward to apply to these data because of the binary outcome defined above. Unconditional logistic regression analysis ${ }^{1011}$ was used. Variables were first included in the model in the categories detailed above. If the log relative risks obtained for different categories of variable (the coefficients from the model) showed a linear or other uniform relation with the variable itself it was then included in the model as a continuous rather than a categorical variable with or without transformation as indicated by the shape of the relation.

Age at radiograph and time between first exposure to asbestos and the radiograph were jointly modelled first because they would be expected to be the most strongly related to the prevalence of radiographic abnormality and the most different between retrospectively collected and current radiographs. The 
remaining variables (except source of radiographs), which all related to exposure at work, could only reasonably be modelled as interaction terms with time since first exposure when this variable was already in the model. To do otherwise would imply that exposure could have had some effect on these men before they were first exposed. For the sake of conceptual simplicity these additional variables were only fitted in categories. Thus the interactions appear as separate terms for time since first exposure in each of these categories.

To allow for, and possibly remove, the effects of misclassification of radiographs on the parameter estimates, ${ }^{12}$ only those subjects in whom both observers agreed on the presence or absence of radiographic abnormality were included for model fitting.

\section{CONFIRMATION OF PREDICTIVE MODEL WITH CURRENT RADIOGRAPHS}

The predictive capability of the final model based on retrospectively collected radiographs was tested on the sample with current radiographs by assigning each person the probability (or risk) of having a radiographic abnormality derived from the model by use of their values of the appropriate variables in the model. The sum of these probabilities then gave the expected number of prevalent cases. This was compared with the observed number of cases based on those in which both observers agreed on presence or absence of radiographic abnormality. A formal goodness of fit test was undertaken by use of the $\mathrm{Hg}$ Statistic of Hosmer and Lemeshow. ${ }^{13}$ This test involves splitting up the $0-1$ risk interval into $g$ (usually equally spaced) groups, calculating expected numbers of "cases" and "non-cases" as just described, and then computing the sum over all $g$ groups of (observed-expected) ${ }^{2} /$ expected, which, if the model is a good fit, should follow a $\mathrm{X}_{\mathrm{g}-2}$ distribution and may be tested accordingly.

The possibility of improvement in the fit of this model to the current sample was examined by further stepwise regression analysis, ${ }^{10}$ including as possible explanatory variables the risk score defined above, all variables examined in the derivation of the retrospective model, and the additionally collected smoking data (categorised as "never" or "ever" smoked). If other variables improved the fit of the model or replaced the risk score in the model the suitability of the model based on retrospectively collected radiographs to the current sample would be in doubt. Similarly if the model with only the risk score included had a constant term different from zero or a regression coefficient different from one, the model suitability would again be in doubt.

\section{ESTIMATION OF CURRENT PREVALENCE OF}

RADIOGRAPHIC ABNORMALITY

Provided that the above criteria for suitability of the retrospectively derived model to the sample of subjects with current radiographs were satisfied, then the individual risk for each male former Wittenoom worker could be calculated for any particular point in time and the mean risk for all workers would provide an estimate of prevalence of pneumoconiosis at that time. The standard error of this estimate, taking account of the standard errors of the model coefficients, ${ }^{14}$ was easily derived (see appendix). This could only reasonably be made as late as 31 December 1980 because searching of the names of all former workers in Australian death registers and electoral rolls has been completed to this date. Extrapolation to later years would be inappropriate because of the unknown change in the population after this date and also because of the unknown effect this change would have on the mean risk and hence the prevalence rate.

Because of substantial incompleteness of follow up, minimum and maximum estimates of prevalence have been made. The first is based on all men known to be alive and living in Australia on 31 December 1980 and the second is based on all men not known to have died or permanently emigrated from Australia by 31 December 1980. Both estimates have excluded all men making a claim for compensation for asbestosis before this date.

\section{Results}

One or more radiographs were retrieved from the Perth Chest Clinic and the teaching hospitals for 859 subjects $(84 \%)$. Of these subjects, 541 had radiographs taken after the date of first employment. Thus $52 \%$ of the original sample had postemployment radiographs that could be used to draw conclusions about the current prevalence of radiographic abnormality. The other 318 subjects with radiographs formed a comparison group with no known exposure to crocidolite at Wittenoom at the time of their radiographs.

Table 1 shows the demographic and employment related characteristics of the subjects, according to their response status. There are significant differences between those with postemployment radiographs and those with only pre-employment radiographs in their duration of employment and total cumulative exposure to asbestos, in the proportions of subjects who were employed in the mill, and in their cumulative exposure up to the date of the radiograph, age at the date of the radiograph, duration of employment to the date of the radiograph, and number with radiographs retrieved from teaching hospitals. Comparisons between those with no radiographs found 
Table 1 Basic characteristics of subjects by time of latest radiograph

\begin{tabular}{|c|c|c|c|c|c|c|c|c|c|}
\hline & \multirow{2}{*}{$\begin{array}{l}\text { No of } \\
\text { radiographs } \\
\text { found }\end{array}$} & \multirow{2}{*}{$\begin{array}{l}\text { Before } \\
\text { starting } \\
\text { work }\end{array}$} & \multirow{2}{*}{$\begin{array}{l}\text { After } \\
\text { starting } \\
\text { work all years }\end{array}$} & \multicolumn{6}{|c|}{ Time of last radiograph (years after starting work) } \\
\hline & & & & $<1$ & $1-4$ & $5-9$ & $10-14$ & $15-19$ & $\geqslant 20$ \\
\hline No of subjects & 179 & 318 & 541 & 168 & 124 & 64 & 44 & 58 & 83 \\
\hline \multirow{2}{*}{$\begin{array}{l}\text { Year of starting work } \\
\text { Age at starting work } \\
\text { Year of birth } \\
\text { Total days worked* } \\
\text { Total cumulative exposure* } \\
\text { fibres/cc years }\end{array}$} & $\begin{array}{c}1959 \\
29 \cdot 6 \\
1929 \\
105\end{array}$ & $\begin{array}{c}1959 \\
27 \cdot 7 \\
1931 \\
65 \dagger\end{array}$ & $\begin{array}{c}1959 \\
29 \cdot 1 \\
1929 \\
126\end{array}$ & $\begin{array}{c}1959 \\
27 \cdot 7 \\
1930 \\
78\end{array}$ & $\begin{array}{c}1958 \\
30 \cdot 3 \\
1928 \\
203\end{array}$ & $\begin{array}{c}1958 \\
28 \cdot 4 \\
1930 \\
165\end{array}$ & $\begin{array}{c}1959 \\
31 \cdot 3 \\
1927 \\
114\end{array}$ & $\begin{array}{c}1961 \\
27 \cdot 8 \\
1933 \\
83\end{array}$ & $\begin{array}{c}1954 \\
30 \cdot 5 \\
1923 \\
183\end{array}$ \\
\hline & 8.5 & $5.3 \dagger$ & 9.6 & 6.4 & $15 \cdot 1$ & $13 \cdot 7$ & $8 \cdot 7$ & 5.6 & $12 \cdot 6$ \\
\hline \multirow{3}{*}{$\begin{array}{l}\text { Cumulative exposure to date of } \\
\text { radiograph* fibres/cc years } \\
\text { Age at radiograph } \\
\text { Total days worked to date of } \\
\text { radiograph* } \\
\% \text { Mill workers } \\
\% \text { With teaching hospital } \\
\text { radiographs }\end{array}$} & - & $\begin{array}{c}0 \dagger \\
27 \cdot 4 \dagger\end{array}$ & $\begin{array}{r}5.5 \\
37.5\end{array}$ & $\begin{array}{r}1 \cdot 1 \\
27 \cdot 8\end{array}$ & $\begin{array}{l}14 \cdot 5 \\
33 \cdot 1\end{array}$ & $\begin{array}{l}13 \cdot 7 \\
35 \cdot 8\end{array}$ & $\begin{array}{r}8 \cdot 7 \\
43.9\end{array}$ & $\begin{array}{r}5 \cdot 6 \\
45 \cdot 1\end{array}$ & $\begin{array}{l}12.6 \\
56 \cdot 3\end{array}$ \\
\hline & -17.9 & $\begin{array}{c}0 \dagger \\
26 \cdot 4 \dagger\end{array}$ & $\begin{array}{l}72 \\
20 \cdot 3\end{array}$ & $\begin{array}{l}13 \\
26 \cdot 2\end{array}$ & $\begin{array}{l}194 \\
14.5\end{array}$ & $\begin{array}{c}164 \\
23 \cdot 4\end{array}$ & $\begin{array}{c}114 \\
20 \cdot 5\end{array}$ & $\begin{array}{l}83 \\
20 \cdot 7\end{array}$ & $\begin{array}{l}183 \\
14 \cdot 5\end{array}$ \\
\hline & - & $0 \dagger$ & $21 \cdot 1$ & 0 & 0 & 1.6 & $31 \cdot 8$ & $53 \cdot 5$ & $81 \cdot 9$ \\
\hline
\end{tabular}

*Geometric mean.

†Significantly different from subjects with radiographs available after starting work.

and those with postemployment radiographs showed no substantial differences in the relevant variables. The existence of fixed retention periods for radiographs in teaching hospitals compared with the indefinite retention policy of the Perth Chest Clinic is shown by the steady increase in the proportion of radiographs retrieved from teaching hospitals with increasing time since first employment..

Kendall's tau statistic for association between observers was 0.50 , indicating moderate agreement (table 2). Most disagreement occurred in radiographs showing minor abnormality, reader 2 tending to grade higher than reader 1 . This confirmed the necessity of using only radiographs with an agreed diagnosis in model derivation. There were 781 such radiographs.

There is a clear increase in the prevalence of radiographic abnormality both with age at the time of the radiograph from ( $0 \%$ at age $15-24$ to $22.2 \%$ at age 65 and over), and years since first exposed (from $1.6 \%$ with no exposure to $26.6 \%$ more than 20 years after first exposure) (table 3). The table shows increases in prevalence with increasing time since first exposed within each age category, implying that there are separate effects for each variable. Similar tables (not shown here) showed similar effects of total cumulative exposure and duration of employment on prevalence of radiographic abnormality. There was no evidence of any exposure effect, however, within one year of starting work. Further subdivision of the data in table 3 by category of total cumulative exposure to asbestos showed a tendency for the prevalence proportions to increase with increasing exposure, although the data were sparse.

The best fitting multiple variable model was one that included a linear increase in log odds of radiographic abnormality with age at radiograph and separate linear increases with the log of days since starting work after the first year for each of the three defined cumulative exposure groups (table 4). No other variable significantly $(p \leqslant 0 \cdot 1)$ improved the fit of the model either alone or in interaction with time since

Table 2 Observer agreement ( 859 latest films)

\begin{tabular}{|c|c|c|c|c|c|c|c|c|c|}
\hline & & \multicolumn{8}{|c|}{ Reader 2} \\
\hline & & $0 /-\& 0 / 0$ & $0 / 1$ & $1 / 0$ & $1 / 1$ & $1 / 2$ & $2 / 1$ & $2 / 2$ & $2 / 3$ \\
\hline Reader 1 & $\begin{array}{l}0 /-\& 0 / 0 \\
0 / 1 \\
1 / 0 \\
1 / 1 \\
1 / 2 \\
2 / 1 \\
2 / 2 \\
2 / 3\end{array}$ & $\begin{array}{r}626 \\
53 \\
22 \\
2 \\
3\end{array}$ & $\begin{array}{r}32 \\
20 \\
3 \\
2\end{array}$ & $\begin{array}{r}26 \\
17 \\
21 \\
6 \\
1\end{array}$ & $\begin{array}{l}3 \\
3 \\
8 \\
1 \\
3\end{array}$ & 2 & $\begin{array}{l}1 \\
1 \\
4\end{array}$ & 1 & 1 \\
\hline
\end{tabular}

Kendall's tau statistic $=\mathbf{0} \cdot 50$. 
Table 3 Radiographic abnormality by age at radiograph and time since first exposed

\begin{tabular}{|c|c|c|c|c|c|c|c|c|c|}
\hline \multirow{2}{*}{$\begin{array}{l}\text { Age at } \\
\text { radiograph }\end{array}$} & & \multirow{2}{*}{$\begin{array}{l}\text { Not } \\
\text { exposed }\end{array}$} & \multicolumn{6}{|c|}{ Time since first exposed (years) } & \multirow{2}{*}{$\begin{array}{l}\text { All time since first } \\
\text { exposed }\end{array}$} \\
\hline & & & $<I$ & $1-4$ & $5-9$ & $10-14$ & $15-19$ & $\geqslant 20$ & \\
\hline $15-24$ & $\begin{array}{l}\text { Normal } \\
\text { Abnormal } \\
\text { Prevalence \% }\end{array}$ & $\begin{array}{r}138 \\
2\end{array}$ & $\begin{array}{r}68 \\
0\end{array}$ & $\begin{array}{r}22 \\
0\end{array}$ & $\begin{array}{l}3 \\
0\end{array}$ & & & & $\begin{array}{r}93 \\
0 \\
0\end{array}$ \\
\hline $25-34$ & $\begin{array}{l}\text { Normal } \\
\text { Abnormal } \\
\text { Prevalence \% }\end{array}$ & $\begin{array}{r}109 \\
2\end{array}$ & $\begin{array}{r}65 \\
1\end{array}$ & $\begin{array}{r}48 \\
2\end{array}$ & $\begin{array}{r}24 \\
3\end{array}$ & $\begin{array}{l}6 \\
1\end{array}$ & $\begin{array}{l}2 \\
0\end{array}$ & & $\begin{array}{l}145 \\
7 \\
4 \cdot 6\end{array}$ \\
\hline $35-44$ & $\begin{array}{l}\text { Normal } \\
\text { Abnormal } \\
\text { Prevalence \% }\end{array}$ & $\begin{array}{r}40 \\
0\end{array}$ & $\begin{array}{r}19 \\
1\end{array}$ & $\begin{array}{r}22 \\
0\end{array}$ & $\begin{array}{r}20 \\
3\end{array}$ & $\begin{array}{r}10 \\
3\end{array}$ & $\begin{array}{r}19 \\
2\end{array}$ & $\begin{array}{l}4 \\
1\end{array}$ & $\begin{array}{l}94 \\
10 \\
9 \cdot 6\end{array}$ \\
\hline $45-54$ & $\begin{array}{l}\text { Normal } \\
\text { Abnormal } \\
\text { Prevalence \% }\end{array}$ & $\begin{array}{r}11 \\
1\end{array}$ & $\begin{array}{l}6 \\
0\end{array}$ & $\begin{array}{r}10 \\
0\end{array}$ & $\begin{array}{l}3 \\
1\end{array}$ & $\begin{array}{r}11 \\
0\end{array}$ & $\begin{array}{r}13 \\
4\end{array}$ & $\begin{array}{r}19 \\
3\end{array}$ & $\begin{array}{c}62 \\
8 \\
11 \cdot 4\end{array}$ \\
\hline $55-64$ & $\begin{array}{l}\text { Normal } \\
\text { Abnormal } \\
\text { Prevalence \% }\end{array}$ & $\begin{array}{l}1 \\
0\end{array}$ & & $\begin{array}{l}3 \\
1\end{array}$ & $\begin{array}{l}3 \\
0\end{array}$ & $\begin{array}{l}2 \\
4\end{array}$ & $\begin{array}{l}3 \\
2\end{array}$ & $\begin{array}{r}13 \\
9\end{array}$ & $\begin{array}{l}24 \\
16\end{array}$ \\
\hline$\geqslant 65$ & $\begin{array}{l}\text { Normal } \\
\text { Abnormal } \\
\text { Prevalence \% }\end{array}$ & & & & $\begin{array}{l}1 \\
0\end{array}$ & $\begin{array}{l}0 \\
0\end{array}$ & $\begin{array}{l}2 \\
0\end{array}$ & $\begin{array}{r}11 \\
4\end{array}$ & $\begin{array}{c}14 \\
4 \\
22 \cdot 2\end{array}$ \\
\hline All ages & $\begin{array}{l}\text { Normal } \\
\text { Abnormal } \\
\text { Prevalence \% }\end{array}$ & $\begin{array}{c}299 \\
5 \\
1.6\end{array}$ & $\begin{array}{c}158 \\
2 \\
1 \cdot 3\end{array}$ & $\begin{array}{c}105 \\
3 \\
2 \cdot 8\end{array}$ & $\begin{array}{c}54 \\
7 \\
11 \cdot 5\end{array}$ & $\begin{array}{c}29 \\
8 \\
21 \cdot 6\end{array}$ & $\begin{array}{c}39 \\
8 \\
17 \cdot 0\end{array}$ & $\begin{array}{l}47 \\
17 \\
26 \cdot 6\end{array}$ & $\begin{array}{c}432 \\
45 \\
9 \cdot 4\end{array}$ \\
\hline
\end{tabular}

starting work. The variable used to indicate the source of the radiograph gave $p=0.102$ with a reduced prevalence of pneumoconiosis among radiographs retrieved from the hospitals.

Actual prevalence proportions and those predicted by the model using the mean ages within each time since first exposed group as shown on table 1 and approximate median times since first exposed in the same groups are shown in fig 1. The only large difference between the actual and the predicted prevalence was in the high exposure group at 15-20 years but this observed prevalence is based on only five subjects. Thus this logistic model appears to fit the data reasonably well. Two important points, however, should be noted; firstly, the model predicts some abnormality for those subjects without asbestos exposure (3.4\% at, for example, age 55$)$ just as there was some abnormality observed in those subjects with radiographs taken at or before starting work and, secondly, the choice of 364 days as a type of latent period was somewhat arbitrary; however, it gave a better fit than two years or no years.

The characteristics of the subjects invited for a current radiographic examination (table 5) show no major differences between responders and nonresponders. There was slightly better agreement between observers for these subjects (Kendall's tau = 0.58 ). There was complete agreement on presence of radiographic abnormality in 10 subjects and its absence in 50 with disagreement in 14. Observed and predicted numbers of abnormal radiographs (consensus films) in the sample are tabulated in table 6, against categories of predicted individual risk of abnormality calculated from the coefficients of table 4. Observed prevalence of abnormality increased with increasing predicted risk and the $\mathrm{Hg}$ statistic of Hosmer and Lemeshow was $0.90(0.5>p>0.25)$ indicating a good fit of the predicted to observed numbers. A stepwise logistic regression for these consensus films showed that no variable (including

Table 4 Final logistic model: consensus radiographs (781 films: 50 abnormal)

\begin{tabular}{|c|c|c|c|c|}
\hline Variable & $\begin{array}{l}\text { Regression } \\
\text { coefficient (b) }\end{array}$ & Standard error of $b$ & Relative risk & $\begin{array}{l}95 \% \text { Confidence } \\
\text { intervals }\end{array}$ \\
\hline \multirow{5}{*}{$\begin{array}{l}\text { Age at radiograph per year } \\
\text { Less than one year since first exposed (or } \\
\text { not exposed): all exposures } \\
\text { Log (days since first exposed: }-364) \text { : } \\
<20 \mathrm{f} / \mathrm{cc} \text { y } \\
\text { Log }(\text { days since first exposed: }-364) \text { : } \\
20-54 \cdot 5 \mathrm{f} / \mathrm{cc} y \\
\text { Log }(\text { days since first exposed: }-364) \text { : } \\
\geqslant 55 \mathrm{f} / \mathrm{cc} y \\
\text { Constant }\end{array}$} & 0.0383 & 0.0135 & 1.039 & $1.012-1.067$ \\
\hline & 0 & - & 1 & - \\
\hline & $0 \cdot 2045$ & 0.0657 & $1 \cdot 227$ & $1.079-1.396$ \\
\hline & 0.2542 & 0.0743 & 1.289 & $1 \cdot 115-1.492$ \\
\hline & $\begin{array}{r}0.3273 \\
-5.4565\end{array}$ & 0.0738 & $\frac{1.387}{-}$ & $\underline{-}^{1.200-1.603}$ \\
\hline
\end{tabular}




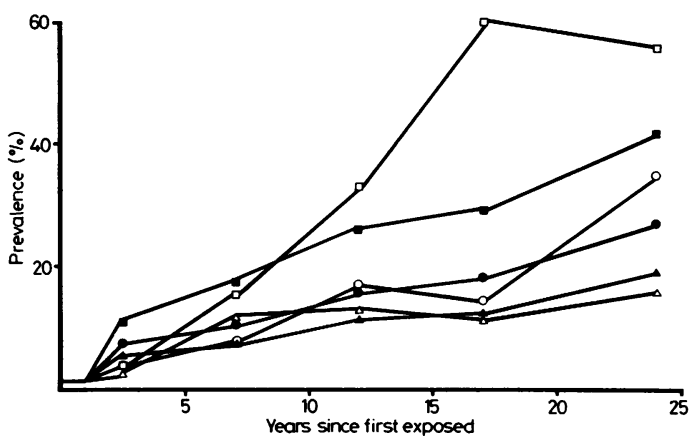

Predicted and observed prevalence percentages of radiographic profusion of small opacities $1 / 0$ or greater by years since first exposed for three levels of exposure.

$\triangle$ Observed $<20 \mathrm{f} / \mathrm{cc} y ; \Delta$ Predicted $<20 \mathrm{f} / \mathrm{cc} \mathrm{y}$;

$\bigcirc$ Observed 20-54 f/cc y; O Predicted 20-54 f/cc y;

$\square$ Observed $\geqslant 55 \mathrm{f} / \mathrm{cc} y$; and $\square$ Predicted $\geqslant 55 \mathrm{f} / \mathrm{cc} \mathrm{y}$.

smoking) significantly ( $p<0.17)$ improved the fit beyond that given by the previously obtained risk score alone. The regression coefficient for the risk score and the constant term were 1.60 and 0.73 respectively with standard errors of 0.91 and 1.31 .

The first population, consisting of 2748 men known to be alive on 31 December 1980, had a mean log risk of -1.630 with a standard error of 0.020 . This translates into an estimate of current prevalence of radiographic abnormality of $16.4 \%$ with $95 \%$ confidence interval $15.9 \%-16.9 \%$, or about 450 men. The second population, consisting of 5241 men not known to be dead or permanently departed from Australia, had a mean $\log$ risk of -1.621 with a standard error of 0.014 . This gives an estimate of current prevalence of radiographic abnormality of $16.5 \%$ with $95 \%$ confidence interval $16 \cdot 1 \%-16.9 \%$, or about 865 men.

The true population of former Wittenoom workers
Table 5 Subjects invited for current radiograph

\begin{tabular}{|c|c|c|}
\hline & $\begin{array}{l}\text { Did not } \\
\text { attend }\end{array}$ & Attended \\
\hline $\begin{array}{l}\text { No of subjects } \\
\text { Year of starting work* } \\
\text { Age at starting work* } \\
\text { Year of birth* } \\
\text { Total days worked } \dagger \\
\text { Total cumulative exposure }(\text { f/cc y) } \\
\% \text { Mill workers } \\
\% \text { Abnormal radiographs } \\
\text { Reader } 1 \\
\text { Reader } 2 \\
\text { Years since starting work } \dagger \\
\text { (to attendance at the Perth } \\
\text { Chest Clinic or } 31 \text { Dec } 1983 \text { ) } \\
\text { Age at radiographł (or at } 31 \text { Dec 1983) } \\
\text { No: ever smoked } \\
\text { No: no previous film } \\
\text { Previous film taken } \\
\text { at or before starting work } \\
\text { <10 years since starting work } \\
10-19 \text { years since starting work } \\
\geqslant 20 \text { years since starting work }\end{array}$ & $\begin{array}{c}26 \\
1959 \\
25 \cdot 7 \\
1933 \\
109 \\
10 \cdot 1 \\
31 \\
- \\
-\end{array}$ & $\begin{array}{c}74 \\
1958 \\
25 \cdot 9 \\
1932 \\
101 \\
8 \cdot 1 \\
24 \\
\\
25 \cdot 7 \\
20 \cdot 3\end{array}$ \\
\hline
\end{tabular}

lies somewhere between these two figures and so it is estimated that there were between 450 and 900 with apparently unrecognised radiographic abnormality at the end of 1980 .

\section{Discussion}

The approach taken in this study has a number of advantages. Firstly, it relied greatly on extant radiographic data, thus simplifying data collection; the logistical problems in doing an Australia wide survey would have been prohibitive. Secondly, the volume of existing data available for modelling the determinants of radiographic abnormality permitted a precise prevalence estimate. Thirdly, incorporating the data from the men who had only pre-employment films pro-

Table 6 Observed and expected numbers of abnormal radiographs among recently invited subjects (60 consensus radiographs)

\begin{tabular}{|c|c|c|c|}
\hline & \multicolumn{3}{|l|}{ Predicted risk } \\
\hline & $0.095-0.149$ & $0.15-0.249$ & $0.25-0.37$ \\
\hline $\begin{array}{l}\text { Observed No: } \\
\text { Abnormal } \\
\text { Normal } \\
\text { Prevalence \% }\end{array}$ & $\begin{array}{c}1 \\
18 \\
5 \cdot 6\end{array}$ & $\begin{array}{l}6 \\
26 \\
18 \cdot 8\end{array}$ & $\begin{array}{c}3 \\
6 \\
33 \cdot 3\end{array}$ \\
\hline $\begin{array}{l}\text { Expected No: } \\
\text { Abnormal } \\
\text { Normal } \\
\text { Prevalence \% } \\
\text { Total }\end{array}$ & $\begin{array}{l}2 \cdot 29 \\
16 \cdot 71 \\
12 \cdot 1 \\
19\end{array}$ & $\begin{array}{l}6.09 \\
25.91 \\
19.0 \\
32\end{array}$ & $\begin{array}{c}2 \cdot 63 \\
6 \cdot 37 \\
29 \cdot 2 \\
9\end{array}$ \\
\hline
\end{tabular}

$\mathrm{Hg}=0.90\left(\chi^{2}{ }_{1}\right.$ gives $\left.0.5>\mathrm{p}>0.25\right)$. 
vided some estimate of the prevalence of radiographic abnormality that could have been due to factors other than exposure to asbestos at Wittenoom.

The principal weakness of the study is the possibility of bias, particularly in the retrospectively collected data. Postemployment radiographs could be located for only $52 \%$ of the sample and in those that could be located there was an inevitable association between availability, age, and time since first exposure. In addition, the proportion of teaching hospital radiographs increased with the passage of time and is likely to be biased by the ill health of the subject. Similarly, Perth Chest Clinic radiographs may be biased towards health because of the requirements for continuing (and presumably, therefore, comparatively healthy) miners to have periodic chest $x$ rays. As for the current sample, it is possible that those living near Perth and included in the sampling frame were not representative of all former workers. It could be that people who feel unwell are more likely to live near good medical care than those who are free of symptoms. In the event the possibility of bias in the radiographs obtained from hospitals reflecting a sicker population was not supported by the data. If anything the prevalence of abnormality suggestive of pneumoconiosis was less rather than more in the hospital than the Perth Chest Clinic radiographs.

In addition, the close agreement between the predicted and actual prevalence of radiographic abnormality in those from whom current radiographs were obtained suggests that the net effects of the biases were roughly the same in the two sets of data and, therefore, probably small.

The prevalence of abnormalities found in the radiographs examined in this study was high and consistent with the degree of exposure to crocidolite of the workforce at Wittenoom. Even with generally short periods of work, $5 \%$ of the workforce were exposed to at least $100 \mathrm{f} / \mathrm{cc} y$ and $11 \%$ of the workforce to at least $50 \mathrm{f} / \mathrm{cc} \mathrm{y}$. The threshold dose of asbestos exposure (and particularly crocidolite exposure) necessary to produce parenchymal fibrosis is uncertain. It has been estimated to be as high as $200 \mathrm{f} / \mathrm{cc}^{15}$ and as low as 50 $\mathrm{f} / \mathrm{cc} \mathrm{y}^{16}$ or even $10 \mathrm{f} / \mathrm{cc} \mathrm{y}^{17}$ These estimates of risk have been based on cumulative exposure gathered over many years. ${ }^{18}$ This is in contrast to the Wittenoom conditions where the average duration of stay was less than four months. The effect of so brief but intense an exposure to crocidolite has not previously been estimated. Among these data there appears to be no "safe dose" as for example among the ten agreed "cases" in the current radiographs total estimated exposure ranged from $1 / 2$ to $120 \mathrm{f} / \mathrm{ccy}$, with three men having total exposures of less than $5 \mathrm{f} / \mathrm{cc} y$

The definite presence of a radiographic abnormality in some subjects with radiographs taken at or before starting work suggests that other dust exposure or smoking may be responsible for some radiographic changes. Smoking has previously been shown to increase the prevalence of abnormal $x$ rays in populations of asbestos workers ${ }^{19}$ and may increase the rate of progression of parenchymal asbestos. ${ }^{20}$ This experience, however, is not universal. ${ }^{21}$ Information on smoking habits was only available from the recently $x$ rayed men and only as a single ever/never smoked variable. The lack of precision in this variable probably nullifies any attempt to quantify the effect of smoking on radiographic abnormality in this study. The lack of any association of this variable with radiographic abnormality after fitting of the retrospectively estimated risk makes it unlikely that the observed radiographic abnormalities were due to smoking to any substantial degree despite the high smoking prevalence (table 5).

The degree of interobserver disagreement in this study reflects the difficulties of classifying radiographs with low profusion scores. This level of disagreement is common when the ILO classification is used for grading the degree of parenchymal asbestosis. ${ }^{22}$ Despite the difficulty of recognising early degrees of parenchymal fibrosis on these plain chest radiographs there is no doubt that a substantial proportion of this workforce have inhaled sufficient amounts of asbestos fibre to produce parenchymal fibrosis. More than 220 subjects with asbestosis have already been compensated from among the workforce of around $7000 .^{1}$

This study relates only to the finding of radiographic changes of small irregular or small rounded opacities as seen in the ILO classification of the pneumoconioses. These changes are not diagnostic of radiographic asbestosis and not necessarily indicative of clinical asbestosis in the participants. The results clearly show, however, a prevalence of uncompensated radiographic abnormality consistent with pneumoconiosis in at least $16 \%$ of former Wittenoom workers that is related to exposure at work and thus must be considered as a likely result of this exposure. A similar experience might be expected in groups of men subject to substantial asbestos exposure who have not been closely followed up.

\section{Appendix}

The quantity calculated for each man in the current population of size $\mathrm{N}$ is

$\mathrm{Y}=\log _{\mathrm{e}}$ [probability of having abnormality/ probability of not having abnormality]

$$
=a+b_{1} x_{1}+b_{2} x_{2}+b_{3} x_{3}+b_{4} x_{4}
$$

where $a$ is the constant and $b_{1}$ to $b_{4}$ the regression coefficients in table 4 , and $x_{1}$ to $x_{4}$ each man's value for the respective variable, assumed fixed. 
Using (1) then

$$
\begin{aligned}
\operatorname{var}(\mathrm{Y})= & \operatorname{var}(\mathrm{a})+\mathrm{x}_{1}{ }^{2} \operatorname{var}\left(\mathrm{b}_{1}\right)+\mathrm{x}_{2}{ }^{2} \operatorname{var}\left(\mathrm{b}_{2}\right) \\
& +\mathrm{x}_{3}{ }^{2} \operatorname{var}\left(\mathrm{b}_{3}\right)+\mathrm{x}_{4}{ }^{2} \operatorname{var}\left(\mathrm{b}_{4}\right)
\end{aligned}
$$

and

$\operatorname{var}\left(\frac{\sum \mathrm{Yi}}{\mathrm{N}}\right)=\frac{\operatorname{var}(\mathrm{a})}{\mathrm{N}}+\sum_{\mathrm{i}=1}^{4} \frac{\operatorname{var}\left(\mathrm{b}_{\mathrm{i}}\right) \sum_{j=1}^{N} \mathrm{x}^{2}{ }_{i j}}{\mathrm{~N}^{2}}=\mathrm{s}^{2}$

Thus because of the asymptotic normality of $\bar{Y}=\sum^{N} Y i / N \quad 95 \%$ confidence limits may be set around $\bar{Y}$ as $\bar{Y} \pm 1.96$ s where $\bar{Y}$ is calculated from either population. These may then be converted back to proportions via the first part of equation (1) and thence to estimated numbers given the two population sizes.

\section{References}

${ }^{1}$ Hobbs MST, Woodward SD, Murphy B, Musk AW, Elder JE. The incidence of pneumoconiosis, mesothelioma and other respiratory cancer in men engaged in mining and milling crocidolite in Western Australia. In: Wagner JC, ed. Biological effects of mineral fibres. Lyon: International Agency for Research on Cancer, 1980. (Sci pub No 30:615-25.)

${ }^{2}$ McNulty JC. Asbestos mining, Wittenoom, Western Australia. In: Major G, ed. Proceedings first Australian pneumoconiosis conference, Sydney, 1968. Sydney: Joint Coal Board, 1968:1-10.

${ }^{3}$ Elder JL. Asbestosis in Western Australia. Med J Aust 1967; 2:579-83.

${ }^{4}$ Layman L. Work and workers' responses at Wittenoom, 1943-66. Community Health Stud 1983;7:1-18.

${ }^{5}$ Cookson WOC, Musk AW, Glancy JJ, et al. Compensation, radiographic changes, and survival in applicants for asbestosis compensation. Br J Ind Med 1985;42:461-8.

${ }^{6}$ International Labour Office. Guidelines for the use of ILO international classification of radiographs of pneumoconiosis. Geneva: ILO, 1980. (Occupational safety and health series, No 22.)
${ }^{7}$ Snedecor GW, Cochran WG. Statistical methods. Iowa: Iowa State University Press, 1972.

${ }^{8}$ Nie NH, Hull GH, Jenkins JG, Steinbrenner K, Bent DH. Statistical package for the social sciences. New York: McGraw Hill, 1975.

${ }^{9}$ Major G. Asbestos dust exposure. In: Major G, ed. Proceedings first Australian pneumoconiosis conference, Sydney, 1968. Sydney: Joint Coal Board, 1968:467-74.

${ }^{10}$ Breslow NE, Day NE. Statistical methods in cancer research. Lyon: International Agency for Research on Cancer, 1980. (Sci pub No 32:192-246.)

${ }^{11}$ Thomas DC. Programme "RISK." Montreal; Department of Epidemiology and Health, McGill University, 1980.

${ }^{12}$ Greenland $\mathrm{S}$. The effect of misclassification in the presence of covariates. Am J Epidemiol 1980;112:564-9.

${ }^{13}$ Lemeshow S, Hosmer DW. A review of goodness of fit statistics for use in the development of logistic regression models. Am J Epidemiol 1982;115:92-106.

${ }^{14}$ Armitage P. Statistical methods in medical research. Oxford: Blackwell, 1971:163-5.

${ }^{15}$ Weill H, Ziskins MM, Waggenspack C, Rossiter CE. Lung function consequences of dust exposure in asbestos cement manufacturing plants. Arch Environ Health 1975;30:88-97.

${ }^{16}$ Berry G, Gilson JC, Holmes S, Lewinsohn H, Roach S. Asbestosis: a study of dose response relationships in an asbestos textile factory. Br J Ind Med 1979;36:98-112.

${ }^{17}$ Finkelstein MM. Asbestosis in long-term employees of an Ontario asbestos-cement factory. Am Rev Respir Dis 1982;125:496-501.

${ }^{18}$ Acheson ED, Gardner MJ. Asbestos: scientific basis for environmental control of fibres. In: Wagner JC, ed. Biological effects of mineral fibres. Lyon: International Agency for Research on Cancer, 1980. (Sci pub No 30:737-54.)

${ }^{19}$ Weiss W. Cigarette smoking, asbestosis, and pulmonary fibrosis. Am Rev Respir Dis 1971;104:223-7.

${ }^{20}$ Wiellat JR, Boutin C, Pietri JF, Fondarai J. Late progression of radiographic changes in Canari chrysotile mine and mill workers. Arch Environ Health 1983;38:54-8.

${ }^{21}$ Selikoff IJ, Nicholson WJ, Lilis R. Radiological evidence of asbestos disease among ship repair workers. Am J Ind Med 1980;1:9-22.

${ }^{22}$ Bohlig H, Gilson JC. Radiology. In: Bogovski P, Gilson JC, Timbrell V, Wagner JC, eds. Biological effects of asbestos. Lyon: International Agency for Research on Cancer, 1973. (Sci pub No 8:25-30.)

\section{Correspondence and editorials}

The British Journal of Industrial Medicine welcomes correspondence relating to any of the material appearing in the journal. Results from preliminary or small scale studies may also be published in the correspondence column if this seems appropriate. Letters should be not more than 500 words in length and contain a minimum of references. Tables and figures should be kept to an absolute minimum. Letters are accepted on the understanding that they may be subject to editorial revision and shortening.

The journal now also publishes editorials which are normally specially commissioned. The Editor welcomes suggestions regarding suitable topics; those wishing to submit an editorial, however, should do so only after discussion with the Editor. 